\title{
O QUE VI, VIVENCIEI E APRENDI PELO CAMINHO? Sobre uma experiência de formação em pesquisa linguística ${ }^{1}$
}

What have I seen, experienced and learned along the way? About a language research training experience

Francisco Renato Lima ${ }^{2}$

RESUMO: Este ensaio teórico foi construído a partir de uma experiência de formação em pesquisa na área de Linguística, vivenciada a nível de doutorado, no Programa de Pós-graduação em Letras (PPGEL), da Universidade Federal do Piauí (UFPI), ao longo do semestre 2019.1. Com o objetivo refletir sobre a pesquisa de doutorado, observando-a na cultura disciplinar da Linguística e no contexto local e global, as discussões empreendidas na disciplina Tópicos Especiais em Linguística, nos permitiram compreender a relevância da formação do pesquisador e o papel das ciências da linguagem como mecanismos de ação e de comprometimento social, político e ideológico com as questões que envolvem a tessitura das práticas discursivas, nas diversas esferas de circulação humana e de domínio ideológico.

Palavras-chave: Letras. Linguística. Formação do pesquisador. Pesquisa linguística. Experiência formativa.

\begin{abstract}
This theoretical essay was built from a research training experience in the area of Linguistics, experienced at the doctoral level, in the Postgraduate Program in Letters (PPGEL), at the Federal University of Piauí (UFPI), throughout the semester 2019.1. In order to reflect on doctoral research, observing it in the disciplinary culture of Linguistics and in the local and global context, the discussions undertaken in the discipline Special Topics in Linguistics, allowed us to understand the relevance of the researcher's training and the role of science sciences. language as mechanisms of action and social, political and ideological commitment to the issues surrounding the fabric of discursive practices, in the various spheres of human circulation and ideological domain.
\end{abstract}

Keywords: Letters. Linguistics. Researcher training. Linguistic research. Formative experience.

\footnotetext{
${ }^{1}$ Atividade apresentada à disciplina Tópicos Especiais em Linguística, do curso de Doutorado em Letras - Linguística, da Universidade Federal do Piauí (UFPI), ministrada pelo professor Dr. Francisco Alves Filho.

${ }^{2}$ Mestre em Letras - Estudos da Linguagem (UFPI). Professor Substituto da Universidade Estadual do Maranhão (UEMA), lotado no Departamento de Pedagogia, do Centro de Estudos Superiores de Timon (CESTI). Coordenador de disciplinas do Centro de Educação Aberta e a Distância (CEAD/UFPI). E-mail: fcorenatolima@hotmail.com
} 


\section{INQUIETAÇÕES INICIAIS}

O título deste texto - de caráter ensaístico - apresenta um questionamento reflexivo acerca de uma experiência formativa e de aprendizagem vivenciada, enquanto aluno especial, na disciplina: Tópicos Especiais em Linguística, do curso de Doutorado em Letras - Linguística, no Programa de Pós-graduação em Letras (PPGEL), da Universidade Federal do Piauí (UFPI).

Neste momento, sinto-me defronte ao espelho, assim como Alice, em "Alice através do espelho e o que ela encontrou lä" (CARROLL, 2015), seis meses após ter vivido a primeira aventura, em "Alice no País das Maravilhas" (CARROLL, 1999). No regresso ao país encantado, a narrativa é tecida a partir da menina brincando com suas gatinhas, enquanto a neve cai lá do lado de fora da janela. Ela faz de conta que o espelho é um portal e, ao atravessá-lo, entra em um mundo bem improvável. Comparando-me a Alice, sou obrigado a questionar-me sobre meus passos e atrelá-los também, aos de outros, com quem dividi o caminho. Neste caso, ao dialogo construído com os oito colegas de sala de aula e o professor ministrante da disciplina, a quem, desde já, dispenso agradecimentos pela acolhida.

O espelho devolve a evidência, revela-se um instrumento mágico que transforma o real em algo maravilhoso, num enigma poético, e permite através destas narrativas aceder a outras realidades. Uma fronteira entre o real e o ilusório que assume por vezes a metáfora de uma "porta" como, em "Alice do outro lado do espelho" de Lewis Carroll em que o conceito de tempo é anulado predominando a inversão da realidade. $O$ desejo de passar para o lado de lá do espelho, do desconhecido, conduz Alice a descobrir que é possível "entrar” no reflexo. Uma metáfora que sustenta o atravessar da infância. Num primeiro momento da narrativa, Alice encontra-se no mundo real e num segundo momento entra nesse mundo que é simultaneamente igual e invertido. Como o reflexo do espelho que devolve uma imagem invertida, os objectos encontram-se dispostos e movimentam-se em sentido contrário. Uma narrativa que se desenvolve pela inversão da realidade, reforçando o conceito de fronteira implícito no reflexo. (SARAIVA, 2011, p. 24) (Grifos meus)

Por meio dessa imersão literária e do que enxerguei pelo reflexo do espelho, retomo o questionamento coletivo que serviu como ponto de partida para o desenvolvimento da disciplina: 'Porque decidiram fazer o doutorado?’ As respostas foram múltiplas e algumas coincidentes. Cá para mim, posso, de modo elementar, destacar algumas motivações:

a) a aquisição de conhecimentos aprofundados na área;

b) a progressão funcional na carreira docente;

c) a autonomia de pesquisa; 
d) e todas as possibilidades de circulação e realização acadêmica, científica, intelectual e social que o título oferece.

Esse último aspecto, que penso até comtemplar os anteriores, e por isso, acredito estar incorrendo no perigo da redundância, me fez lembrar Bernstein (2003, p. 76), quando diz que "títulos [acadêmicos] merecem ser estudados por eles mesmos, não como meras formas estéticas, mas também como significadores das relações de poder no campo intelectual" (Grifos meus). Foi neste sentido que as atividades da disciplina Tópicos Especiais em Linguística foram desenvolvidas, partindo do objetivo geral de 'refletir sobre a pesquisa de doutorado, observando-a na cultura disciplinar da linguística e no contexto local e global'.

\section{A PESQUISA LINGUÍSTICA E O COMPROMETIMENTO COM A FORMAÇÃO DO PESQUISADOR: RETRATOS DE UMA EXPERIÊNCIA}

A pesquisa na área da linguagem hoje - diferentemente do início do século XX, quando os estudos de Saussure atribuíram a Linguística o estatuto de ciência - vivencia um momento de renovação e atualização das bases que alicerçam o seu fazer metodológico. O modo puramente abstrato e estrutural vem desde as três últimas décadas do referido século, perdendo lugar para o florescer das interações, que, no canteiro das obras linguísticas, assumiu o estatuto de uma linguística da enunciação, identificada por um pluralismo de correntes teórico-metodológicas e abordagens, que, no geral, coincidem ao considerarem que os sujeitos não prescindem da língua, mas constituem-se nela e por meio dela, nas marcas de subjetividade e de interação dialógica que o singularizam nas situações de linguagem.

A visão afiançada por essa perspectiva é de que a língua/linguagem é uma forma de interação, repleta de intenções de dizer, visto que na realização do ato enunciativo, os sujeitos realizam suas escolhas linguísticas, evidenciando a singularização no discurso, construída a partir de seus conhecimentos de mundo, do lugar social de onde falam e dos propósitos que pretendem alcançar. Para tanto, articulam e organizam ideias no plano textual-discursivo, produzindo significados sociais nos contextos em que atuam e construindo uma identidade como protagonistas das situações de interação construídas pelo e no ato enunciativo.

Dentre essas 'situações' estão aquelas possíveis de serem alcançadas pelo pesquisador em seu processo de imersão pelo mundo da pesquisa científica e que, portanto, nos interessam bastante nesta reflexão, uma vez que, durante o desenvolvimento da referida disciplina, pomo-nos a pensar sobre que escolhas, caminhos, percursos, metodologias e condutas de pesquisa temos tomado na execução do projeto de pesquisa de doutorado em andamento.

Particularmente, meu projeto volta-se sobre um tema que pesquiso desde 2015 e de lá para cá, tenho redefinido pontos de vistas e opções teórico-metodológicas para explorá-lo. Em linhas gerais, trata- 
se do estudo da relação médico-paciente (LIMA, 2016), buscando entender como ocorre a compreensão entre esses sujeitos em contextos de consulta médica, partindo das categorias: i. eventos e práticas de letramentos sociais (LIMA, 2017a; 2017b; 2018a); e ii. atividades de retextualização (LIMA, 2018b; 2019). Esta última, em particular, tem sido meu objetivo de pesquisa, ao me propor a 'analisar atividades de retextualização de receitas médicas empregadas por pacientes em contextos institucionais'.

No entorno desse objetivo, busquei fixar um lugar social na condução das discussões feitas na disciplina, que a meu ver, trouxe contribuições bastante elucidativas e qualificativas para os projetos de doutorado da turma. Sobre isso, cabe, de antemão, um adendo relevante: a experiência do mestrado foi, e é, bastante produtiva e, digamos, preparatória, para a inserção no mundo da pesquisa - talvez a chamada 'pesquisa de ponta', embora nós, da Linguística, no Brasil particularmente, ainda não tenhamos conseguido alcançar tal status -, mas, a maturidade mais avançada do pesquisador só é relativamente atingida no doutorado. 'Relativamente', por quê? Porque embora o período de quatro anos nos permita adentrar com mais profundidade a um tema e a um cenário de pesquisa - como bem o fazem os etnógrafos -, é somente a vivência e a aplicação, após o doutorado, que vão aproximando o pesquisador de um estágio mais aprofundado, crítico e criativo de conceber e proceder a pesquisa.

Essa reflexão foi bastante alimentada durante nossas discussões. Desse modo, sinto-me com fôlego para pensar que a possibilidade de realização de uma pesquisa a nível de doutorado é também, uma possibilidade de ampliar horizontes teóricos e buscar trazer algum tipo de inovação para o tema e área de pesquisa. Um desafio hercúleo, em virtude de estarmos imersos em um contexto de tanta propagação do conhecimento, viabilizado pelo processo de globalização e internacionalização das culturas, que se faz sentir pela desenfreada proliferação dos recursos tecnológicos, digitais e midiáticos. Esse fato pode nos criar uma série de encruzilhadas e nos deixar 'sem chão', seja para: a) conseguir elaborar uma proposta relativamente nova, diante de tantos 'já ditos'; ou para b) nos dispersar facilmente, diante de tantas possibilidades de leitura/pesquisa, um caminho semelhante ao do 'hiperleitor', eu diria.

Penso que no campo da Linguística, uma alternativa feliz para desfazer tal imbróglio, seja talvez, a busca por avizinhamentos teórico-metodológicos, fugindo de uma visão unilateral e reducionista. Esse desafio implica, em primeiro plano, conhecer a cultura disciplinar de nossa área e o grande guarda-chuva, que são as subáreas ou correntes teóricas e abordagens da Linguística; e, em segundo plano, conhecer a cultura disciplinar de outras áreas, seja no campo mesmo das Ciências Humanas e Sociais (como a História, a Geografia, a Antropologia, a Sociologia etc.), no campo das Ciências Exatas (como a Física, a Química, a Matemática, as Engenharias etc.) ou no campo da Saúde (como a Medicina, a Enfermagem, a Odontologia, a Fonoaudiologia etc.). Conhecidas às especificidades que aproximam ou distanciam essas áreas/disciplinas, será possível então, estabelecer interfaces, aproximações, diálogos inter/trans/multi/pluridisciplinares, a fim de consolidar um modo mais maleável, funcional, dinâmico e plástico de fazer pesquisa linguística no Brasil. 
Feitas estas tessituras - produtos diretos da experiência de amadurecimento intelectual vivenciada na disciplina - sinto-me convocado a complexa tarefa de responder a alguns questionamentos específicos, no sentido de aperfeiçoar a condução de seu processo, quando ofertada em semestre posteriores e também, avaliar a experiência vivida, aspecto este, que acredito já ter deixado algumas pegadas nos parágrafos que antecederam a este.

Nesse intento, aglutino o primeiro e o segundo desses questionamentos, por considerar que, para ambos, tenho 'respostas' que se entrelaçam a contento. Vejamos: 1) O que pode ser revisto na proposta? Por quê?? 2) O que poderá ser acrescentado? Por que? Considero que para o nível de ensino em que foi ofertada (doutorado), a abordagem didático-pedagógica e de aprofundamento do conteúdo foi bastante satisfatória. As discussões, bem fundamentadas em aportes teóricos de literatura nacional e internacional atualizada, trouxeram para cada aluno, uma possibilidade singular de enxergar a realização de sua pesquisa. Dessa maneira, elas deixavam sempre um 'gostinho de quero mais', por isso, penso que a carga horária poderia ser ampliada, fato que academicamente se justifica, pela constatada importância e contribuição que a disciplina trouxe a essa primeira turma de Doutorado em Letras - Linguística (PPGEL/UFPI). Assim, com mais tempo de aula, sua oferta deve ser replicada, com a oportunidade de acrescentar mais referenciais teóricos e aprofundar os já existentes.

O terceiro questionamento, inquiriu se: 3) Howve impacto das discussões em relação ao modo como en concebia a elaboração de um projeto? Quais? Como? Minha matrícula na disciplina coincidiu com a feitura do projeto de doutorado, que estava em andamento, em fase de ajustes finais, e, portanto, as leituras, as discussões e as orientações compartilhadas tornaram-se um divisor de águas, no sentido de definir escolhas que até então eram motivo de dúvidas e incertezas; reconhecer meu papel como 'autor' no processo de elaboração de um projeto de pesquisa; e adquirir mais segurança e 'relativa certeza' quanto aos empreendimentos futuros que a pesquisa na área de linguagem pode me oferecer.

O quarto questionamento, buscou saber sobre 4) Outros temas que podem ser discutidos: práticas de leitura relacionadas a pesquisa e elaboração de projeto; práticas de escrita; as funcõoes e as interlocucõoes ligadas a um projeto de pesquisa; expectativas sobre o que é uma tese; a questão das culturas e subculturas disciplinares. Em face de tantas possibilidades necessárias de exploração do conhecimento, sugiro: a) uma imersão ainda maior em resultados de pesquisas realizadas por grandes pesquisadores e de universidades renomadas, com impacto mundial em nossa área; b) mais leituras e análises dos gêneros acadêmicos, como projeto de pesquisa, artigo científico, dissertação de mestrado, tese de doutorado, entre outros, em uma perspectiva sociorretórica, que habilite o olhar do doutorando para o modo como são (des) construídas e aceitas socialmente as diversas culturas disciplinares; e c) maior investimento em experiências práticas, de coleta e análise de dados, por meio da escrita do gênero artigo científico, corroborando a cultura da aplicação, que, no geral, as pesquisas sociais comtemplam. Todas essas alternativas constituem caminhos animadores para alavancar a prática de pesquisa dos doutorados. 


\section{INQUIETAÇÕES FINAIS}

Feito esse trajeto, volto novamente a Alice, e, mais uma vez, "através do espelho", penso que, de alguma forma, por meio da escrita deste ensaio, consegui deixar transparecer o reflexo do pesquisador que fui, sou e serei. Olho para os caminhos que tenho tomado, os que pretendo seguir e me convenço da necessidade de assumir sempre um compromisso ético, crítico, reflexivo e, sobretudo, transformador, por meio da pesquisa linguística, que, nada mais é, que um modo de enxergar, ser e praticar nossa postura cidadã e política no mundo.

\section{REFERÊNCIAS}

BERNSTEIN, Basil. A pedagogização do conhecimento: estudos sobre recontextualização. Tradução Maria de Lourdes Soares e Vera Luiza Visockis Macedo. Cadernos de Pesquisa, n. 120, p. 75-110, novembro/2003.

CARROLL, Lewis. Alice no país das maravilhas. Tradução Ana Maria Machado. 2. ed. São Paulo: Ática, 1999.

CARROLL, Lewis. Alice através do espelho e o que ela encontrou lá. Tradução Cynthia Beatrice Costa. São Paulo: Poetisa, 2015.

LIMA, Francisco Renato. Letramentos em contextos de consulta médica: um estudo sobre a compreensão na relação médico-paciente. 2016. 254 f. Dissertação (Mestrado em Letras - Estudos da Linguagem) - Centro de Ciências Humanas e Letras. Universidade Federal do Piauí, Teresina, 2016.

LIMA, Francisco Renato. Letramento e letramentos: uma análise de práticas sociais letradas em contextos hospitalares a luz dos novos estudos do letramento. Caminhos em Linguística Aplicada, Taubaté, v. 16, p. 110-131, $2017 \mathrm{a}$.

LIMA, Francisco Renato. A compreensão na comunicação entre médicos e pacientes: um estudo em contextos de letramentos. In: BRITO, Djane Oliveira de; LIMA, Francisco Renato (Org.). Escritos sobre linguagem, discurso e interação. Teresina: EDUFPI, 2017b. p. 33-58. 
LIMA, Francisco Renato. Letramento, dialogismo e compreensão na interação entre médicos e pacientes. In: LIMA, Francisco Renato; SILVA, Marcos Helam Alves da (Org.). Letramento, gênero e discurso: entre a oralidade e a escrita. Teresina: EDUFPI, 2018a. p. 53-81.

LIMA, Francisco Renato. Atividades de retextualização do gênero receita médica em contextos de comunicação médico-paciente. Entrepalavras, Fortaleza, v. 2, p. 156-173, 2018b.

LIMA, Francisco Renato. Letramentos e retextualização em contextos de consulta médica: um estudo sobre a compreensão na relação médico-paciente. Campinas: Mercado de Letras, 2019.

SARAIVA, C. A. C. dos S. Espelhos e reflexos: estratégias de representação e (des) construção do corpo e da identidade feminino. 2011. 113 f. Dissertação (Mestrado em Pintura). Faculdade de Belas Artes: Universidade de Lisboa, 2011. 